\title{
DESIGN METHODOLOGY AND PERFORMANCE STUDIES OF A FLEXIBLE ELECTROTEXTILE SURFACE
}

\author{
Ozan KAYACAN, ${ }^{* 1}$ Özlem KAYACAN, ${ }^{1}$ Ender BULGUN, ${ }^{2}$ Burçin ESER, ${ }^{3}$ Maşuk PAMUK, ${ }^{3}$ \\ ${ }^{1}$ Dokuz Eylül University, Textile Eng. Dept. Tinaztepe Kampusu Buca, Izmir, 35397, Turkey \\ ${ }^{2}$ Izmir University of Economics, Faculty of Fine Arts and Design, \\ Sakarya Cad. No.156 Balcova Izmir, 35330, Turkey \\ ${ }^{3}$ Uniteks Textile Company, A.O.S.B. 10039 Sk. No.26 Cigli, Izmir, 35620, Turkey \\ *ozan.kayacan@deu.edu.tr
}

\begin{abstract}
:
'The smart textiles' concept has to develop products based not only on design, fashion and comfort but also in terms of functions. The novel electro-textiles in the market open up new trends in smart and interactive gadgets. 'Easy to care and durability' properties are among the most important features of these products. On the other hand, wearable electronic knitwear has been gaining the attention of both researchers and industrial sectors. Combining knitting technology with electronics may become a dominant trend in the future because of the wide application possibilities. This research is concerned primarily with the design methodology of knitted fabrics containing electrically conductive textiles and especially in-use performance studies. The structural characteristics of the fabrics have been evaluated to enhance the performance properties.
\end{abstract}

\section{Keywords:}

Electro-textiles, conductive yarns, flexible electronics, in-use performance

\section{Introduction}

The term 'smart textiles' defines materials with advanced responsive properties enabling them to sense, actuate and/or control. The development of smart wear is a new challenge for the textile and clothing industry: it has to develop products based not only on design, fashion and comfort concepts but also in terms of functions[14]. Moreover, these products must be easy to care and durable[24]. Combining textiles with electronics has become a promising realm in the future development of textiles. A number of researches have been conducted to exploit the potential applications, such as sports $[4,15,20]$, healthcare[11,23], and so on. However, the growth of wearable electronic textiles in the market has been retarded. The reasons may be attributed to the poor appearance of current products and that consumers may consider the products to be 'technical' rather than 'garments'.

Development of electrically conductive textile materials is one of the key issues in recent smart textile research. This is a field of innovation that broadened the scope of the traditional textile and apparel products to high-tech textiles, designed to meet specific needs[14], involving different technologies[9, 3] and produced according to required properties, like personal protection [19, 17, 10], safety[14], leisure[7] or health wear[12]. Just as in classical electronics, the construction of electronic capabilities for electrotextiles requires the usage of conducting pathways on fabric constructions. Hence, the development of such hybrid products mainly depends on the conductive pathways in terms of material selection and application.

Wearable electronic knitwear has recently been gaining the attention of both researchers and industrial sectors. Combining knitting technology with electronics may become a dominant trend in the future $[3,9,16]$. The knitting, made with conductive yarn, is one of the essential building blocks for textile-based intelligent garments. Knitwear exhibits high flexibility and comfort, making it a good candidate for applications in sports, medicine, and other areas that incorporate electro-conductive components[4]. Textile-based electronic circuits have become a key element in recent developments in intelligent textiles. The general methodology used to design this kind of flexible electro-textile surfaces can be grouped into two major topics. The first is to fulfill the needs of the comfort and appearance properties of an ordinary textile product while the second is to meet the functional requirements.

This approach has been focused to develop a fabric design by using conductive yarns to create novel intelligent and functional applications for dressing/garments. Previous experimental studies $[22,13]$ revealed that the formation of electrical circuits in textile structures can be performed in various ways such as weaving, stitching, embroidery of conductive threads on fabric substrates, knitting of conductive threads along with non-conductive threads, printing or deposition and chemical patterning of conductive elements on textile substrates. The 
knitwear could achieve better results in performance than other methods[16]. The main advantages of producing conductive knitted textiles for the purpose of establishing electronic circuits are enormous owing to continuous conductive pathways without any interruption. Also, by using kntting technology, large-area structures can be produced quickly and cost-effectively [8].

\section{Experimental}

\subsection{Material}

In this study, stainless steel yarns have been used to form conductive paths in the fabric construction. The textilebased circuit formation has been produced in circular knitting machine. The samples are in the form of simple fleecy fabric with the dimensions of $20 \times 20 \mathrm{~cm}$. The cotton yarns are used as base yarns while the conductive yarns have been knitted as fleecy yarns. The in-use performance mainly depends on the performance properties of textile-based conductive pathways[1, 24, 25].

In this study, two-thread fleecy fabrics were produced. Ne 30/1 Co yarn has been used as base yarn and Ne 20/1 Co yarn as fleecy yarn (Figure 1). Fabric samples were produced on single bed circular knitting machine ( $E=28$ gauge, 32" diameter).

Also at the reverse side of the fabrics, the inox yarns (stainless steel fibres) were used as conductive yarns. These yarns have a yarn count of $\mathrm{Nm} 15 / 1$ and $36 \Omega$ per $10 \mathrm{~cm}$ linear resistances. The conductive yarns contain stainless steel fibre of diameter $8 \mu$ and the yarns were knitted at different systems as given in Table 1, and also the front views of the fabrics are given in Figure 2.

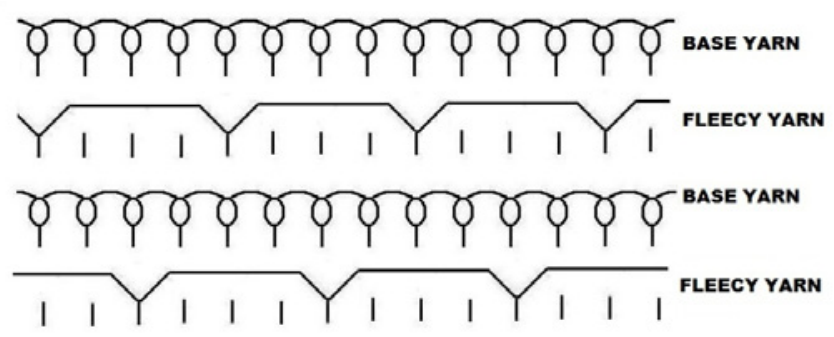

Figure 1: Fabric construction

Table 1: Knitting notation of two-thread fleecy fabric

\begin{tabular}{|c|c|}
\hline Fabric code & The systems having conductive yarns \\
\hline F1 & $\begin{array}{c}\text { The conductive yarns are knitted as } \\
\text { fleecy yarn at every } 24^{\text {th }} \text { system. }\end{array}$ \\
\hline F2 & $\begin{array}{c}\text { The conductive yarns are knitted as } \\
\text { fleecy yarn at every } 48^{\text {th }} \text { system. }\end{array}$ \\
\hline F3 & $\begin{array}{c}\text { The conductive yarns are knitted as } \\
\text { fleecy yarn at every } 96^{\text {th }} \text { system. }\end{array}$ \\
\hline
\end{tabular}

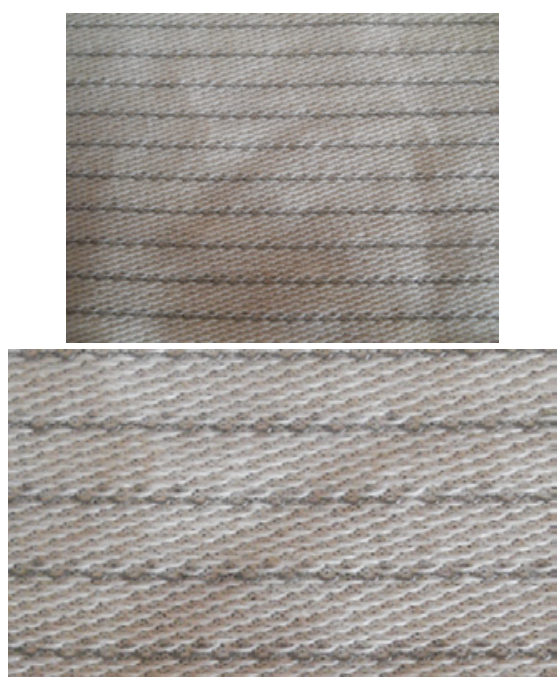

Figure 2: General views of sample fabrics

The fabric densities and yarn tensions were set to the most appropriate levels in order to avoid problematic cases during production. The course and wale densities of conductive knitted fabrics are given in Table 2.

Table 2: Fabric properties

\begin{tabular}{|c|c|c|}
\hline Fabric code & $\begin{array}{c}\text { Course density } \\
\text { (courses/cm) }\end{array}$ & $\begin{array}{c}\text { Wale density } \\
\text { (wales/cm) }\end{array}$ \\
\hline F1 & 18.7 & 12.2 \\
\hline F2 & 17.3 & 13.6 \\
\hline F3 & 18.7 & 12.7 \\
\hline
\end{tabular}

\subsection{Method}

In order to investigate the effects of various physical and chemical processes on the electrical performances of conductive yarns that is placed in to the fabric structure, dyeing process, washing cycles and pilling tests have been performed on the samples.

All fabric samples were bleached before dyeing process. Bleaching of the samples were carried out according to following recipe: $1 \mathrm{~g} / \mathrm{l}$ wetting agent, $4 \mathrm{~g} / \mathrm{l} \mathrm{NaOH}$ (Ak-Kim, Istanbul-Turkey), $2 \mathrm{~g} / \mathrm{l} \mathrm{H}_{2} \mathrm{O}_{2}$ (Ak-Kim, Turkey, 50\%), $3 \mathrm{~g} / \mathrm{l}$ detergent (Solay DLM-K, Busan A.Ş.-Bursa-Turkey). After the bleaching process, the samples were rinsed two times for 2 minutes; $1 \mathrm{~g} / \mathrm{l}$ catalase (Terminox Ultra Novazyme) was applied for 10 minutes and then treated with $2 \%$ of cellulase enzyme (VESPIL328) for 25 minutes then rinsed two times with cold water. The dyeing process is described in Figure 3. After the dyeing process, all fabric samples were rinsed three times for 2 minutes with cold water, neutralised with acetic acid for 3 minutes. After rinsing with cold water, the samples were soaped at $60^{\circ}$ for 2 minutes, rinsed two times for 2 minutes. Fixation washing was applied for 10 minutes. The samples were rinsed with cold water two times for 2 minutes and softened with $5 \%$ softening agent for 5 minutes. All wet processes were achieved in drum type dyeing machine (Arda Makine, Istanbul-Turkey). All chemicals were used without purification. 


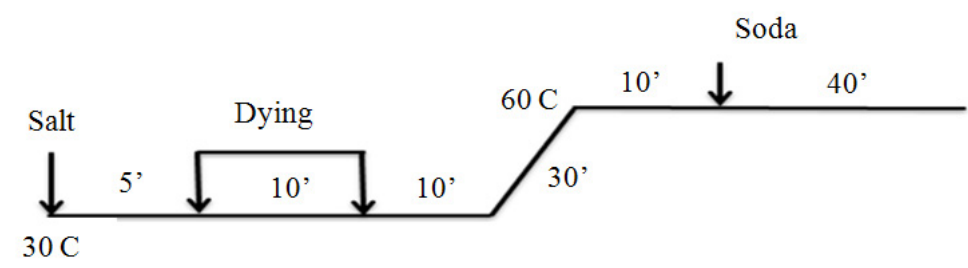

Figure 3: Stages and recipe of dyeing process

Pilling tests were performed according to Standard ISO 129451 [6] by using SDL-Atlas M227 test device (ICI Pilling Box).

Five washing cycles were carried out by using a domestic laundry machine with a detergent without optical brightener at $40^{\circ} \mathrm{C}$ according to Standard EN ISO 6330 [5]. Finally, all fabrics were laid in the free form on a flat surface for drying procedure.

Before and after each process (dyeing, pilling, washing cycles), resistance values of the conductive yarns within the fabric structure have been measured. Arithmetic means of 10 individual measurements of the conductive lines tested have been presented as measured values.

The values of resistances were measured by using 2-probe method with a digital multimeter DM-6016 produced by Lutron with a range of $0.001 \Omega$ to $20 \mathrm{M} \Omega$ and an accuracy of $\leq 1 \%$. The device selected the voltage automatically to measure resistances depending on their magnitude. The values measured were taken after $15 \mathrm{~s}$ from the beginning of measuring. The samples consist of several conductive yarns in the fabric structure but the whole fabric surface was not a conductive structure completely. Therefore, instead of surface resistivity, this study focuses on the influences of some physical and chemical processes on the resistivity of individual conductive yarns in the fabric surface. For this reason, the 2-probe method has been performed to measure yarn resistivity. The appropriate grasp-type probe for yarns has been used. Ten conductive lines in the fabric structure have been taken into account respectively and the probes have been placed into both ends of conductive lines with a distance of $10 \mathrm{~cm}$. Hence, the unit of the results has been presented as $\Omega / 10 \mathrm{~cm}$. The measurements were carried out in a standard conditioned room in order to provide the equality of the masurement

\section{Results and Discussions}

The conductive yarns have been knitted in different structures as fleecy yarns within the fabric structure as shown in Table 1. At the starting phase of the study, the resistance values of raw fabrics (prior to first process) were measured. The initial resistance values of the raw fabrics are given in Table 3.

First of all, the dyeing process has been carried out. The resistance values of the conductive yarns were measured after the dyeing process. The results are shown in Table 4.
To observe any possible effects in conductivity due to fibre breakage and abrasion, pilling tests have been performed after dyeing processes. The results of the resistance measurements after pilling tests are shown in Table 5.

After pilling tests; five washing cycles were carried out. Before and after each washing cycle, the samples were investigated about the effects of each cycles on the resistance values of the conductive yarns. The resistance values of the conductive yarns were measured as shown in Table 6.

In order to compare the resistance levels of the conductive pathways, the results were evaluated as given in Figure 5. As seen in the results, the resistance values increased

Table 3: Resistance values of raw fabrics $(\Omega / 10 \mathrm{~cm})$

\begin{tabular}{|c|c|c|c|}
\hline & F1 & F2 & F3 \\
\hline Avr. & 34.90 & 33.40 & 33.60 \\
\hline
\end{tabular}

Table 4: Resistance values of the yarns after dyeing process $(\Omega / 10 \mathrm{~cm})$

\begin{tabular}{|c|c|c|c|}
\hline & F1 & F2 & F3 \\
\hline Avr. & 73.90 & 81.50 & 80.10 \\
\hline
\end{tabular}

Table 5: Resistance values after pilling tests $(\Omega / 10 \mathrm{~cm})$

\begin{tabular}{|c|c|c|c|}
\hline & F1 & F2 & F3 \\
\hline Avr. & 84.70 & 85.60 & 94.20 \\
\hline
\end{tabular}

Table 6: Resistance values of the yarns after each washing cycle $(\Omega / 10 \mathrm{~cm})$

\begin{tabular}{|c|c|c|c|}
\hline & F1 & F2 & F3 \\
\hline $\begin{array}{c}\text { After } 1^{\text {st }} \\
\text { cycle. }\end{array}$ & 190 & 161 & 158 \\
\hline $\begin{array}{c}\text { After 2 } \\
\text { cycle }\end{array}$ & 205 & 155 & 147 \\
\hline $\begin{array}{c}\text { After } 3^{\text {rd }} \\
\text { cycle }\end{array}$ & 216 & 131 & 116 \\
\hline $\begin{array}{c}\text { After } 4^{\text {th }} \text { Cycle } \\
\text { After } 5^{\text {th }} \\
\text { cycle }\end{array}$ & 211 & 116 & 116 \\
\hline
\end{tabular}


significantly after the dyeing process and also after pilling tests. Dyeing process, as a chemical reaction, increases the resistance levels of the conductive yarns. The fibres are affected in negative way because of the conditions of dyeing process. The resistance values increase more then two times after dyeing. Also, pilling test has a negative effect on resistance values and causes a slight increase. One of the possible reasons for this increase in the resistance values of the pathways after pilling is the loss of some metal fibres due to abrasion impacts during the pilling tests. One way to ensure that stainless steel fibres do not slide from the yarn could be to give extra twists to the yarn[24].

First washing cycle also has a great impact, as observed in dyeing process. It is observed that the resistance values of the conductive pathways is doubled after first washing cycle. The increasing tendency continues till the end of the third washing cycle for the sample F1. But for F2 and F3, the resistance values showed a slight decrease during washing cycles. For $\mathrm{F} 1$, the resistance levels are approximately the same values for the beginning and the final stage of washing cycles (after first and fifth cycle).

The results showed that washing cycles do not have a deep impact to the resistance levels for $F 1$. The washing cycles have affected F2 and F3 more. When we examine the construction of the samples in terms of conductive yarn layout, it can be seen that the conductive yarns are much more close to each other in F1, comparing to F2 and F3. The negative effects decrease as the distance between the conductive pathways increases.

As stated above, the pathways in the fabric construction are made of conductive yarns containing stainless steel filaments. The surface of stainless steel materials are pleated. in a characteristic manner, by using chromium(III) oxide $\left(\mathrm{Cr}_{2} \mathrm{O}_{3}\right)$ layer, to protect the material from oxidation when it is exposed to air. Even though the layer is impervious to water, it might get damaged due to mechanical actions during physical and chemical processes. The increase in resistance can be explained through the damage of the metallic yarns, whereby electrical current flow is obstructed[18]. The corrosion, called crevice corrosion[2], is promoted and the electrical resistance increases.
Finally, if we evaluate the general influence of physical and chemical processes and tests, the results showed that the resistance levels were affected by the dyeing test and first washing cycle the most.

The main goal of the study is to investigate an innovative functional fabric design with conductive yarns and determine the resistance values of the conductive pathways before and after physical and chemical processes in order to evaluate in-use performance of the functional fabric. These efforts will also help to develop a design model for creating wearable electronic textiles that can provide certain functionalities by using conductive yarns in the future studies.

The 'easy-to-care' and 'in-use performances' are among the essential building blocks for textile-based intelligent garment developments[21].

\section{CONCLUSIONS}

The integration of smart functionality into clothing and other textile products will radically change the culture surrounding these products, fundamentally altering people's relationships with them and the way they use them. Smart functionality will also have an impact on the way products are designed and the materials developed.

Smart and interactive products with active electronic functions are the hybrid products between the textile and electronic. Combining textiles with electronics has become a promising realm in the future development of textiles. To ensure their wide usage in the daily life, these products must be easy to care and durable. It should be noted, however, that ordinary textile processes and repeatetitive washing cycles of such conductive yarns resulted in degradation of the electrical properties.

In this study, it was observed that the dyeing test and first washing cycle have a great effect on the resistance values. Different number of washing cycles affected the samples in different ways. Also, creating a knitted electrical fabric that exhibits integrity, looks and feels as an ordinary fabric is one of the deliverables of this study. Flexible and durable fabric

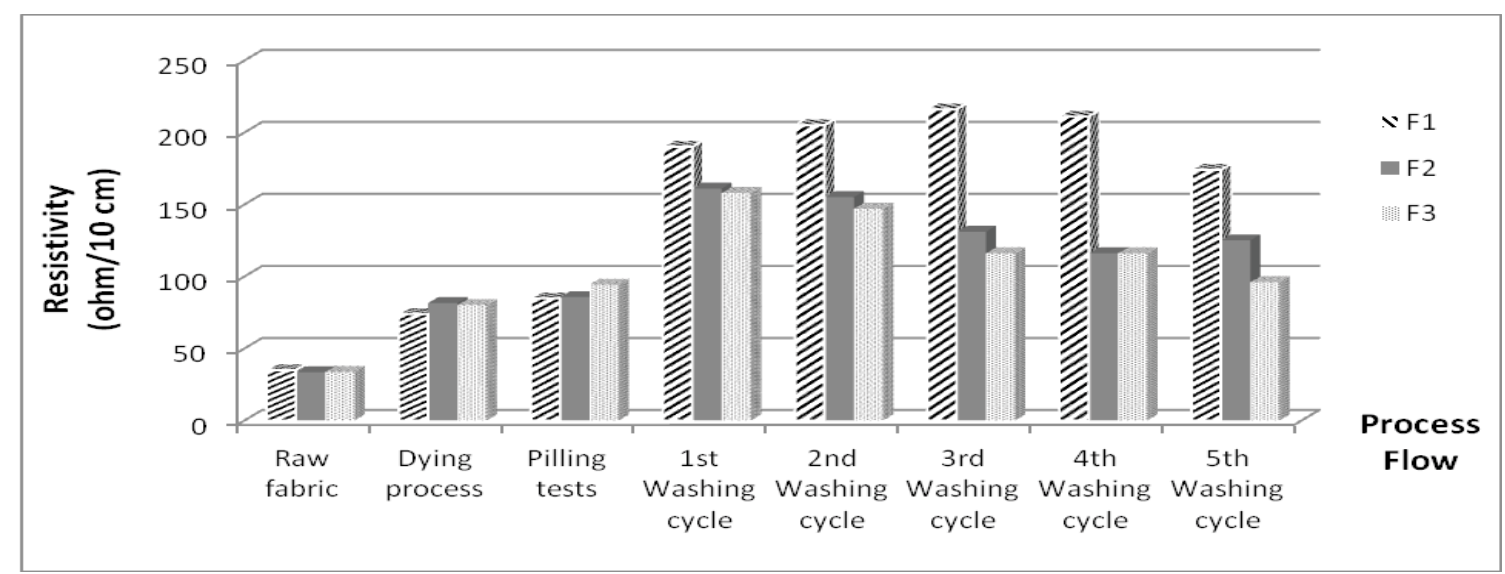

Figure 4: Resistance measurements results after each process/test/cycle $(\Omega / 10 \mathrm{~cm})$. 
development methodology and performance studies have been investigated.

In order to test the functional properties and durabilities of various types of metal-based conductive yarns/pathways such as silver, copper and stainless steel-based samples for daily usage, the performance tests under different conditions should be performed and evaluated.

\section{ACKNOWLEDGEMENTS}

The authors would like to thank to TUBITAK 'The Scientific and Technical Research Council of Turkey' for financial support under TEYDEB Project Number 9120 004. Also, the authors would like to express their appreciation to Uniteks for their financial and technological support during the study.

\section{References}

[1] Arai,E., Arai, T., (Eds).(2007). Mechatronics for Safety, Security and Dependability in a New Era. Elsevier (England).

[2] Baboian, R. (Ed.) (2005) Crevice Corrosion in Corrosion Tests and Standards: Application and Interpretation 2ndEd. ASTM International (Baltimore)

[3] Baurley, S., (2004). Interactive and Experiential Design In Smart Textile Products And Applications. Journal Personal and Ubiquitous Computing, 8 (3-4), pp. 274 - 281

[4] Bonfiglio, A., DeRossi, D. (Ed.). (2011). Wearable Monitoring Systems. Springer (New York)

[5] BS EN ISO 6330 (2012) Textiles - Domestic washing and drying procedures for textile testing

[6] BS EN ISO 12945-1 (2001) Textiles - Determination of fabric propensity to surface fuzzing and to pilling - Part 1 : Pilling box method

[7] Chen, A.C., (2013). Designing for the daily-life applications with functional textiles. 5th Int. Con. of the Int. Assoc. of Soc. of Design Research, http://design-cu.jp/iasdr2013/ papers/1730-1b.pdf

[8] Ethridge, E., Urban, D.(2002). Electrotextiles. International Journal of High Speed Electronics and Systems, 12(02), 365-369

[9] Knittel,D., Schollmeyer,E., (2009). Electrically highconductive textiles. Synthetic Metals, 159, 1433-1437

[10] Lam Po Tang,S.(2007). Recent Developments in Flexible Wearable Electronics for Monitoring Applications. Transactions of the Institute of Measurement and Control, 29(3/4), 283-300
[11] Lopez, G., $\quad$ Custodio, V., Moreno,J.I., (2010). LOBIN: E-Textile and Wireless-Sensor-Network- Based Platform for Healthcare Monitoring in Future Hospital Environments. IEEE Transactions on Information Technology in Biomedicine, 14(6), 1446-1458

[12] Lymberis A., Gatzoulis L., (2006). Wearable health systems: From smart technologies to real applications. Conf, Proc. IEEE Eng Med. Biol. Soc., 6789-6792

[13] Mattila, H.(Ed.), (2006). Intelligent Textiles and Clothing. Woodhead Publishing Ltd.(Cambridge)

[14] McCann,J., Bryson,D.(Ed.),(2009). Smart Clothes and Wearable Technology. Woodhead Publishing (Cambridge)

[15] McLoughlin, J., Cashman, P., Ledbury, J., (2013). A Smart Textile For Measuring The Impact Of Energy Used In Competitive Contact Sports. The Textile Institute Int. Conf.: Adv. in Functional Textiles, 25 - 26th July 2013, Manchester, UK. (http://eprints.hud.ac.uk/18533/)

[16] Power,E.J., Dias, T., (2003). Knitting of Electroconductive Yarns. IEE Eurowearable, $55-60$

[17] Ramdayal, Balasubramanian K, (2013). Advancement In Textile Technology For Defence Application. Defence Sci. Jour., 63(3), 331-339

[18] Schwarz,A., Kazani,I., Cunny,L., Hertleer,C., Ghekiere,F. (et al.),(2011). Electro-conductive and Elastic Hybrid Yarns-The Effects of Stretching, Cyclic Straining and Washing on Their Electro-conductive Properties. Materials and Design, 32, 4247-4256

[19] Scott, A.R.(Ed.), (2005). Textiles For Protection. Woodhead Publishing(Cambridge)

[20] Shishoo,R.(Ed.), (2005). Textiles in Sports. Woodhead Publishing Ltd.

[21] Slade, J., et all,(2002). Washing of Electrotextiles. Proceedings of the Materials Research Society Symposium(MRS), 736, 99-108

[22] Song, H.Y., Lee, J.H., Kang, D., Cho, H., Cho, H.S. (et al.), (2010). Textile Electrodes Of Jacquard Woven Fabrics For Biosignal Measurement. The Journal of The Textile Institute, 101(8), 758-770

[23] Van Langenhove, L.(Ed.), (2007). Smart Textiles for Medicine and Healthcare, Materials, Systems and Applications. Woodhead Publishing Ltd.(Cambridge)

[24] Varnaite,S., Katunskis, J., (2009). Influence of Washing on the Electric Charge Decay of Fabrics with Conductive Yarns. Fibers and Textiles in Eastern Europe, 17,(5)76, pp.69-75

[25] Wang,F., Lee,H., (2010). Evaluation of the performances of the Electrically Heated Clothing. Annals of Occupational Hygiene, 54, 117-124 